\title{
Isotropic freeze casting of through-porous hydroxyapatite ceramics
}

\author{
Zhen WU, Zhengren ZHOU, Youliang $\mathrm{HONG}^{*}$ \\ National Engineering Center for Biomaterials, Sichuan University, Chengdu 610064, China
}

Received: August 22, 2018; Revised: December 11, 2018; Accepted: December 14, 2018

(C) The Author(s) 2019.

\begin{abstract}
It has well known that hydroxyapatite (HA) is a kind of excellent materials for biomolecular absorption and separation, and the absorption and separation performances of HA would be improved if HA had been processed into desirable porous structures. In this paper, we reported on the combination of gel casting and freeze casting to develop the through-porous hydroxyapatite ceramic monoliths. Experiments demonstrated that the gel-containing freeze casting technique was an isotropic pore-forming technique and could prepare the near-net-shape forming green bodies with good mechanical strength no matter what the HA content in green bodies was. Further green body sintering formed the through-porous ceramics whose grain size, pore size, and porosity depended on and could be controlled by the content of HA in green bodies. The formation of through-pores in ceramics resulted from the gels and water in green bodies, which acted as the templates of the pores with size $<1 \mu \mathrm{m}$ and the pores with size $>1 \mu \mathrm{m}$, respectively. The gel-freeze casting technique is simple, repeatable, and cost-effective, therefore being hopeful for industrial applications.
\end{abstract}

Keywords: gel-freeze casting; through-pores; hydroxyapatite (HA); ceramics; near-net-shape

\section{Introduction}

It is well known that the applications and performances of hydroxyapatite ( $\left.\mathrm{HA}, \mathrm{Ca}_{10}\left(\mathrm{PO}_{4}\right)_{6}(\mathrm{OH})_{2}\right)$ are structurally dependent. In particular, the HA ceramics with abundant through-pores are important in many practical applications, e.g., bioengineering [1], chromatography [2], catalysis [3], gas sensing [4], water treatment [5], etc. At the same time, it is also important to process HA into special shapes or devices in practical applications. For example, in high performance liquid chromatography (HPLC), it has been well accepted that the HPLC columns in the formation of monoliths with abundant through-pores

\footnotetext{
* Corresponding author.

E-mail: hyl@scu.edu.cn
}

$(0.1-10 \mu \mathrm{m})$ have better performance than conventional microsphere-packed model because the monolithic column with abundant through-pores can decrease back pressure and shorten the separation time [6]. Therefore, the choice or creation of a right processing method to prepare the apatite monoliths with desirable through-pores and in the defined monolithic shapes is very important.

Nowadays, various methods have been developed to prepare the through-porous HA ceramic monoliths, including the use of hard spheres [7] or organic foams [8] as pore templates, gas foaming [9], and freeze casting [10]. However, these methods had weak abilities to prepare the monolithic and near-net-shape forming HA ceramics. For example, in the use of polymethyl methacrylate (PMMA) microspheres to prepare the through-porous ceramics, the cracks would form during the green body drying because the 
existence of PMMA hard spheres impeded the monolithic shrinkage of green bodies during drying $[7,11]$. The use of gas foaming and freeze casting would form the green bodies with weak mechanical strength, which easily resulted in the deformation of green bodies during sintering [12,13].

To achieve the monolithic HA ceramics with the defined shape and good mechanical strength, a variety of forming techniques have been developed, including pressing [14], slip casting [15], injection molding [16], and gel casting [17]. Among these forming methods, the gel casting, reported firstly by Young et al. [17], now has become an important ceramic forming technique, in which a high-quality complex-shaped ceramic with good mechanical properties can be achieved [18]. Such method also has been used to process the HA ceramic monoliths. Nevertheless, the attention of using gel casting mainly was focused on manufacturing the compact ceramics. Although Sepulveda et al. [19] and Ramay and Zhang [20] have attempted to prepare the porous HA ceramics by combining the gel casting method with the pore templates (hard PMMA microspheres or polyurethane sponge), the shortcomings resulted from the pore templates that would cause the sintered ceramics to crack had not been avoided.

Herein, continuous efforts are performed to prepare the through-porous HA ceramic monoliths by the use of the gel-containing freeze casting technique (called as gel-freeze casting). The combination of the gel casting and the freeze casting is hypothesized to have complementary advantages to respective technique and can overcome the shortcomings resulted from the pore template method. In this work we investigated in detail the formation of through-pores based on the gel-freeze casting technique.

\section{Materials and methods}

\section{1 Materials}

HA powders, consisted of $\sim 50 \mathrm{~nm}$ HA nanocrystals, were prepared using a co-precipitation method [21] and a ball milling dispersion. Hydroxypropyl methylcellulose (HPMC) was used as bonding agent, and sodium polymethacrylate (PMA) as dispersant. The components of the gel casting process were reactive organic monomers: monofunctional acrylamide (AM), and difunctional methylenebisacrylamide (MBAM). Ammonium presulphate (APS), and N,N,N',N'tetramethylethylenediamine (TMED) were used as the initiator and catalyst, respectively. All chemical reagents were purchased from Chengdu Kelong Chemical Agent Corporation. All slurries were aqueous, and deionized (DI) water was used in all the experiments.

\section{2 Preparation of through-porous HA ceramics}

At first, as shown in Scheme 1, the gel-containing HA green bodies were prepared. The HA slurry was prepared by adding HA powders, HPMC, PMA, AM, and MBAM into DI water. Table 1 shows the amount of chemicals added to DI water to formulate the HA slurry. The prepared slurry was de-agglomerated by ball milling for $1 \mathrm{~h}$ and subsequently de-aired under

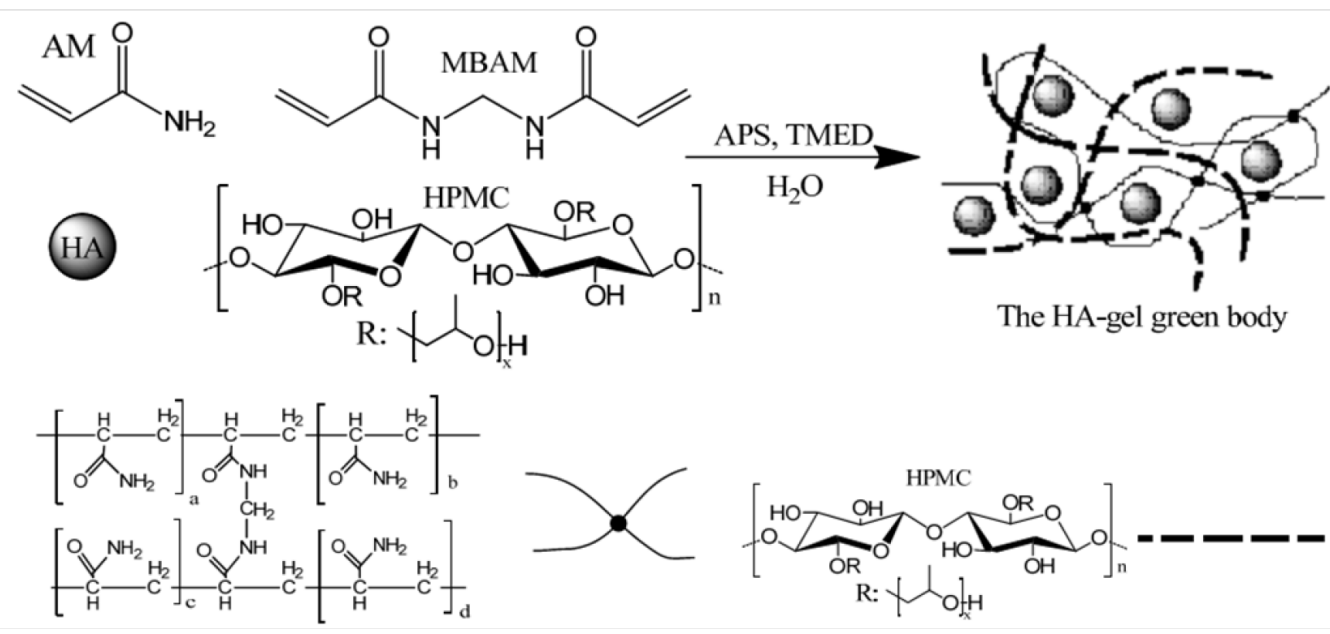

Scheme 1 Schematic illustration of the HA-gel green body preparation. At first, HA powders, HPMC, AM, PMA, and MBAM were added into DI water to form the HA slurry. Then APS and TMED were added to the HA slurry to polymerize and crosslink the organic gel. In the crosslinked gel, the solid dot in the illustration denotes the crosslinking point of PAM. 
Table 1 Amount of chemicals added to DI water to formulate the HA slurry

\begin{tabular}{lc}
\hline Component & Amount \\
\hline DI water & $30.0 \mathrm{~g}$ \\
HA powders & $5 \mathrm{~g} \leqslant \leqslant 40 \mathrm{~g}$ \\
PMA & $1.0 \mathrm{wt} \% \mathrm{of} x$ \\
HPMC & $1.0 \mathrm{~g}$ \\
AM & $2.0 \mathrm{~g}$ \\
MBAM & $0.3 \mathrm{~g}$ \\
APS & $0.1 \mathrm{~g}$ \\
TMED & $0.1 \mathrm{~g}$ \\
\hline
\end{tabular}

vacuum until no further release of air bubbles from the slurry. APS and TMED subsequently were added to the HA slurry to polymerize the polyacrylamide monomers. The prepared HA slurry was cast into the Teflon cube molds $(10 \mathrm{~mm} \times 10 \mathrm{~mm} \times 100 \mathrm{~mm}$, or $15 \mathrm{~mm} \times 15 \mathrm{~mm}$ $\times 50 \mathrm{~mm}$ ), which then were placed in a $40{ }^{\circ} \mathrm{C}$ nitrogen chamber (in order to avoid oxygen contamination which may inhibit the polymerization process) to react for $24 \mathrm{~h}$.

The polymerized cube green bodies $(10 \mathrm{~mm} \times$ $10 \mathrm{~mm} \times 100 \mathrm{~mm}$ ) were treated using two methods. (i) Freeze-dried using a lyophilizer $\left(-56{ }^{\circ} \mathrm{C}\right.$, LGJ-10N, Beijing Yaxing Ika Technol. Dev. Co., China). In detail, the as-prepared green bodies were frozen under $-20{ }^{\circ} \mathrm{C}$ for $24 \mathrm{~h}$ at first, and then the frozen samples were transferred in the lyophilizer for $72 \mathrm{~h}$. (ii) Dried naturally at room temperature for 1 week. After drying, the prepared green bodies were heated at a rate of $2{ }^{\circ} \mathrm{C} / \mathrm{min}$ to the defined temperature (from 850 to $\left.1100{ }^{\circ} \mathrm{C}\right)$. The samples were heated at this temperature for the defined time (1-6 h) to prepare the HA ceramics. Then the sintering temperature was decreased to room temperature by $2{ }^{\circ} \mathrm{C} / \mathrm{min}$.

In a control experiment, $30.0 \mathrm{~g}$ HA powders, $1.0 \mathrm{~g}$ HPMC were added to $30.0 \mathrm{~g}$ DI water to prepare the HA slurry, which then was cast into mold. After drying at room temperature for 1 week, the green bodies were sintered by repeating above sintering procedure to prepare the compact HA ceramics.

\section{3 Characterization}

To measure the shrinkage change of green bodies or ceramics, the volume of nature-dried, freeze-dried, or sintered samples were measured. The volume shrinkage ratio of green bodies was calculated by the formula $S(\%)=\left[\left(V_{\mathrm{I}}-V_{\mathrm{D}}\right) / V_{\mathrm{I}}\right] \times 100$, where $V_{\mathrm{I}}$ denotes the volume of the initial green bodies, $V_{\mathrm{D}}$ the volume of the dried green bodies. The volume shrinkage ratio of ceramics was calculated by the formula $S(\%)=\left[\left(V_{\mathrm{G}}-V_{\mathrm{C}}\right) / V_{\mathrm{G}}\right] \times$ 100 , where $V_{\mathrm{G}}$ denotes the volume of green bodies, $V_{\mathrm{C}}$ the volume of the sintered ceramics.

The microstructures of samples were observed using a scanning electron microscope (SEM, Hitachi S-4800). Before observation, the samples were coated with gold using an ion sputter (E-1010, Hitachi). A mercury intrusion porosimetry (MIP, micromeritics Auto Pore IV9500) was used to measure the cumulative pore volume, average pore diameter, pore diameter distribution, and porosity of the sintered samples. At the same time, the Archimedes method was used to test the pore volume of the sintered and unsintered samples. During measurement, N,N-dimethylformamide was used instead of water to avoid the water absorption or dissolution of organic components in the unsintered samples. The compression mechanical tests were carried out at room temperature with a $20 \mathrm{kN}$ loading capacity universal testing machine (AG-IC, Shimadz) at a speed of $3.0 \mathrm{~mm} / \mathrm{min}$, and the load was applied until ceramics were cracked. For the compression mechanical test, the samples were prepared into $8 \mathrm{~mm}$ $\times 8 \mathrm{~mm} \times 15 \mathrm{~mm}$. For each sample five ceramic blocks were prepared to measure their compression strength, and the measured data were presented as means \pm standard deviations (s.d.).

\section{Results and discussion}

Although it has been well demonstrated that the gel casting was a near-net-shape forming technique on the fabrication of ceramics, its ability was limited by the content of ceramic powders. Some papers have reported only when the content of ceramic powders in green bodies was high enough, could the near-net-shape forming of ceramics be achieved [20,22]. Indeed, our experiments confirmed such conclusion substantially. As shown in Fig. 1(a), when the content of HA in green bodies was lower than $23 \mathrm{wt} \%$, the deformed green bodies formed, and only when the HA content went up $38 \mathrm{wt} \%$, the deformation of green bodies was impeded. By comparison, a combination of the gel casting technique and freeze-drying treatment avoided completely the deformation of green bodies resulted from the low HA content, as can be seen from Fig. 1(a). The volumes of green bodies were retained by and 
large whatever the HA content changed.

On the other hand, the use of the freeze casting method to fabricate the porous ceramics also has a shortcoming, that is, after sublimation of the frozen liquid, the achieved green bodies had weak mechanical strength so that it is difficult to transfer the green bodies for further sintering [13]. However, when such method combines with the gel casting, as shown in Fig. 1(b), the mechanical strength of the gel-freeze green bodies increased markedly, even the decrease of the HA content did not influence largely the compressive strength of green bodies. The high mechanical strength of green bodies, obviously can be attributed to the gel within green bodies, which had polymerized into network and could improve largely the ability of the HA green bodies to resist crushing [17,18,22,23].

The internal microstructures of the freeze-dried green bodies were observed using an SEM and the porosity was tested using an Archimedes method, and the resulting images are shown in Fig. 2 and Table 2. When the HA content was very higher (55 wt $\%)$, the green bodies had relatively low porous structure with porosity $45.95 \%$. A decrease of the HA content ( $48 \mathrm{wt} \%$ ) increased pore size and poroisty in green bodies. The magnified SEM image inserted in Fig. 2(b) shows that the pore diameter was $1-2 \mu \mathrm{m}$ with porosity $68.09 \%$ (Table 2). The HA content in green bodies further decreased to $38 \mathrm{wt} \%$, larger pores $(\sim 2-5 \mu \mathrm{m})$ with increasing porosity (72.41\%) formed (Fig. 2(c)). However, excessive decrease of the HA content ( $23 \mathrm{wt} \%$ ) formed abundant superlarge pores $(50-150 \mu \mathrm{m}$, see Fig. 2(e)) and reduced the quantity of the pores with the diameter $<5 \mu \mathrm{m}$ extremely (Fig. 2(d)). Nevertheless, the porosity $(80.52 \%)$ increased extremely.
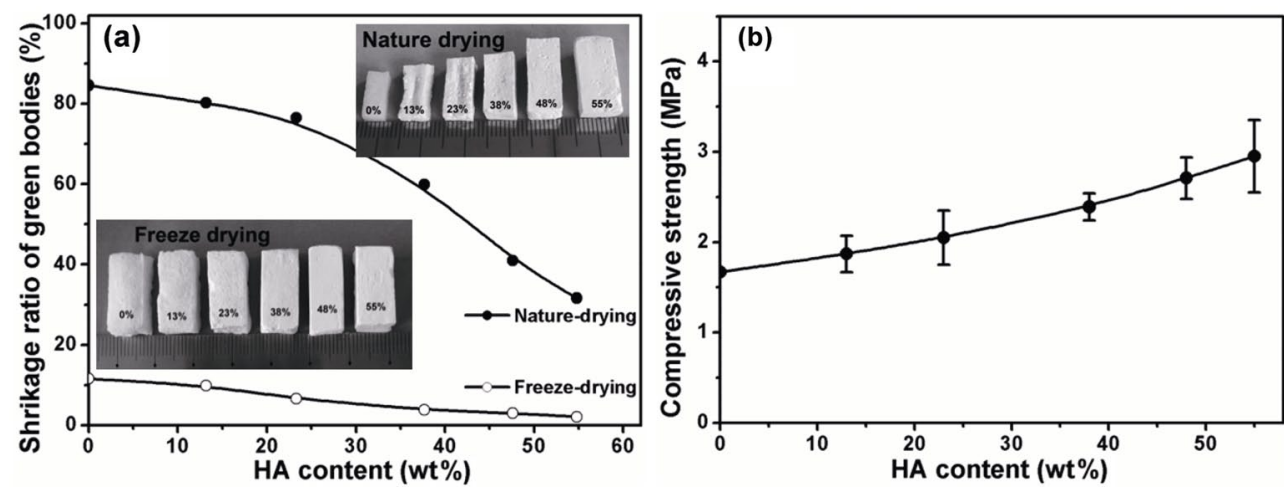

Fig. 1 (a) Effect of the HA content and drying methods on the near-net-shape forming of green bodies. (b) Compressive strength as a function of the HA content in the freeze-dried green bodies (mean \pm s.d., $n=5$ ).
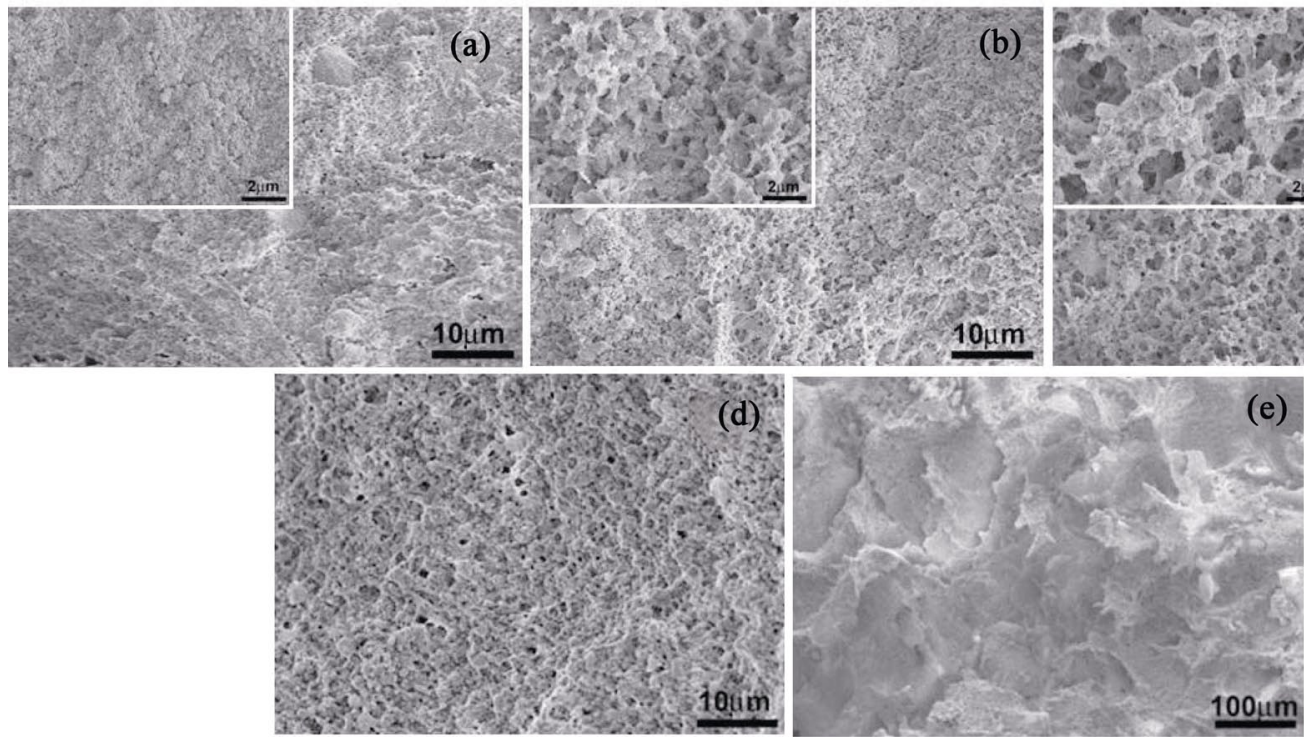

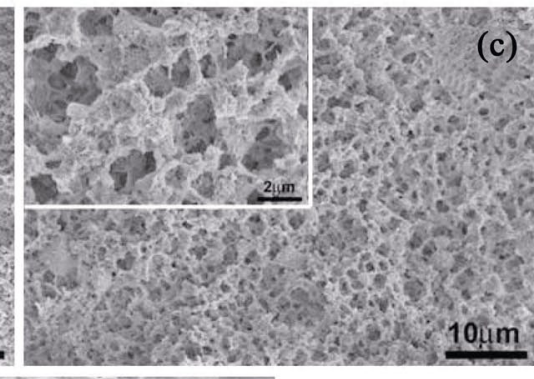

(e)

Fig. 2 SEM images of the gel-containing freeze HA green bodies. The content of HA in green bodies was: (a) $55 \mathrm{wt} \%$, (b) 48 $w t \%$, (c) $38 \mathrm{wt} \%$, and (d, e) $23 \mathrm{wt} \%$. 
Table 2 Properties of the gel-freeze HA green bodies

\begin{tabular}{cccc}
\hline Sample & Average grain size $(\mathrm{nm})$ & Pore size $(\mu \mathrm{m})$ & Porosity (Archimedes) $(\%)$ \\
\hline $55 \mathrm{wt} \%$ HA-contained green bodies & 50 & 0 & 45.95 \\
$48 \mathrm{wt} \%$ HA-contained green bodies & 50 & $1-2$ & 68.09 \\
$38 \mathrm{wt} \%$ HA-contained green bodies & 50 & $2-5$ & 72.41 \\
$23 \mathrm{wt} \%$ HA-contained green bodies & 50 & $50-150$ & 80.52 \\
\hline
\end{tabular}

Generally, the ceramics prepared via the anisotropic freeze casting or unidirectional freezing method would form the lamellar-structure pores in green bodies $[10,13,24,25]$. Such structural pores resulted from water, which formed lamellar ice templates during the anisotropic freeze casting/unidirectional freezing process of green bodies. However, in our samples, no lamellar structures were emerged. It suggested that the gel components in green bodies played important roles in impeding water to crystallize into the lamellar ice. Therefore, in our examples, our method in fact is an isotropic freeze casting process [25].

The freeze-dried green bodies were further sintered at $1100{ }^{\circ} \mathrm{C}$ for $6 \mathrm{~h}$ to achieve the through-porous HA ceramics, as can be seen from Fig. 3 and Table 3. SEM images inserted in the MIP curves show that the microstructures of all HA ceramics were constructed by the HA grains and the interspace-constructed pores, and the MIP/Archimedes test further demonstrated that most and possibly even all as-formed pores were through-pores in all ceramics. Nevertheless, the pore size and porosity of the prepared ceramics changed in inverse proportion to the content of HA in green bodies. The HA ceramics prepared from the green bodies with $55 \mathrm{wt} \%$ HA presented smallest pore size $(0.58 \mu \mathrm{m})$ and lowest porosity $(48.56 \%)$, and with the decrease of the HA content in green bodies, the pore size and porosity of the HA ceramics increased successively. In
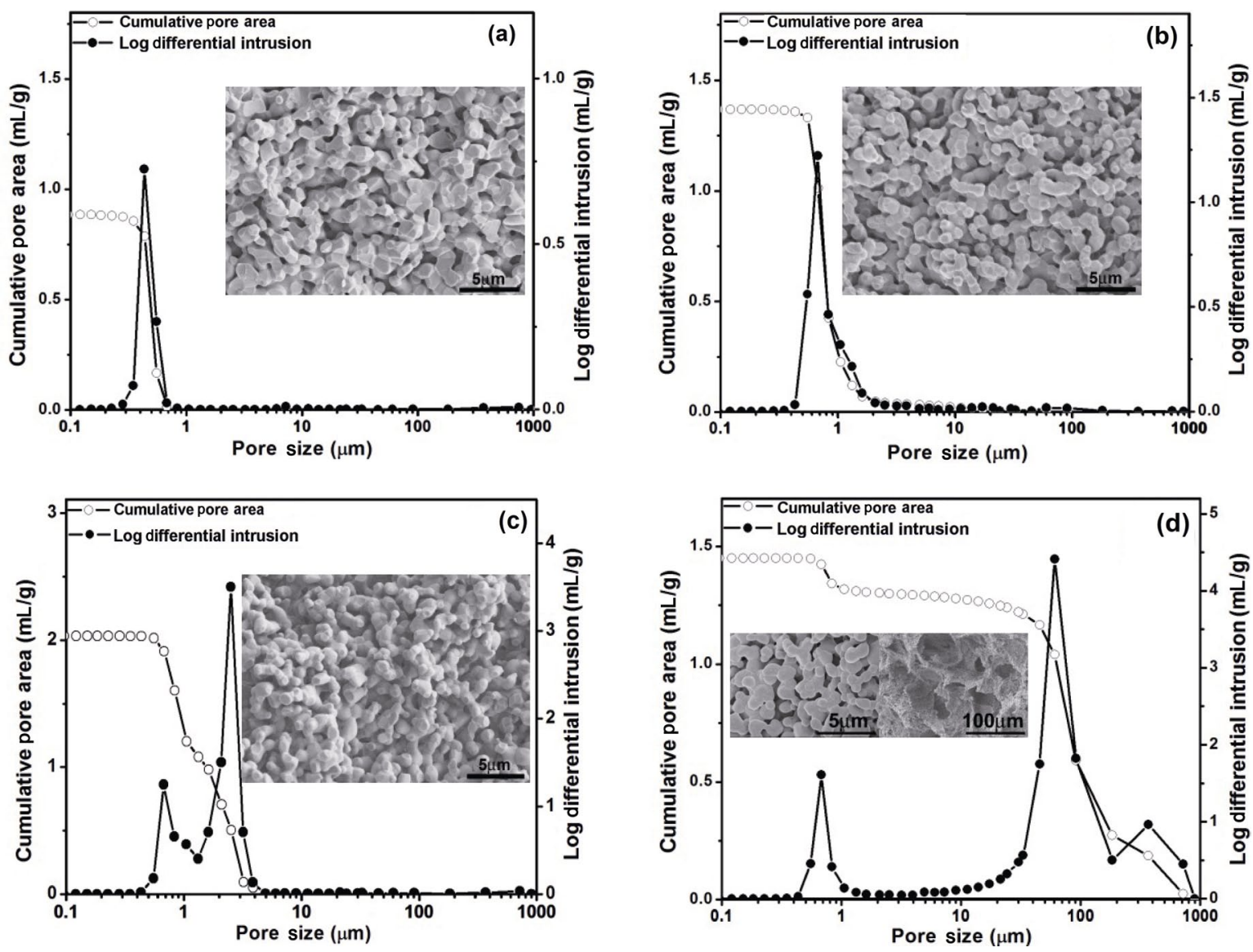

Fig. 3 MIP and SEM images (inserted in MIP) of the through-porous HA ceramics prepared from the green bodies with (a) 55 wt $\%$, (b) $48 \mathrm{wt} \%$, (c) $38 \mathrm{wt} \%$, and (d) $23 \mathrm{wt} \% \mathrm{HA}$. 
Table 3 Properties of the HA ceramics prepared by the gel-freeze casting and gel casting (all ceramics were sintered at $1100{ }^{\circ} \mathrm{C}$ for $6 \mathrm{~h}$ )

\begin{tabular}{ccccc}
\hline Sample & HA content $(\mathrm{wt} \%)$ & Average grain size $(\mu \mathrm{m})$ & Average pore size $(\mu \mathrm{m})$ & Porosity $(\mathrm{MIP} /$ Archimedes $)(\%)$ \\
\hline & 55 & 1.04 & 0.58 & $48.56 / 47.34$ \\
Gel-freeze cast ceramic & 48 & 0.82 & 1.4 & $63.61 / 69.39$ \\
& 38 & 0.83 & 2.35 & $71.35 / 76.0$ \\
& 23 & 0.81 & 79.15 & $95.5 / 90.0$ \\
\hline Gel cast ceramic & 48 & 0.85 & 0.72 & $45.54 / 44.5$ \\
\hline
\end{tabular}

comparison with the green bodies (Fig. 2 and Table 2), the grain size, pore size, and porosity of the sintered ceramics changed extremely. Especially, the throughpores also emerged in the HA ceramics prepared from the green body with high HA content (55 wt\%). In addition, the MIP results showed that in all ceramics the pores with size $<1 \mu \mathrm{m}$ were indicated. Such results imply that the gel within green bodies also acted as the roles of pore templates.

To demonstrate above speculation, the green bodies with $48 \mathrm{wt} \%$ HA were prepared using the gel casting technique alone and subsequently the corresponding ceramics were prepared via high temperature sintering at $1100{ }^{\circ} \mathrm{C}$ for $6 \mathrm{~h}$. Before sintering, the green bodies indicated compact microstructure, and no pores formed within matrix (Fig. 4(a)). Such microstructure of the gel cast green bodies, similar as the $55 \mathrm{wt} \% \mathrm{HA}$ contained green bodies prepared by the gel-freeze casting (Fig. 2(a)), could be attributed to the water evaporation and shrinkage of green bodies during nature-drying (Fig. 1(a)). In contrast, in the $55 \mathrm{wt} \%$ HA contained and gel-freeze cast green bodies, the compact microstructure could be attributed to the high HA content because when the HA content decreased, the pores formed (Figs. 2(b)-2(d)). After the gel cast green bodies were sintered, the formed ceramics indicated abundant through-pores (average pore size
$0.72 \mu \mathrm{m})$, as shown in Fig. 4(b) and Table 3. In comparison with the corresponded ceramics prepared via the gel-freeze casting (Fig. 3(b)), the pores with diameter 1-2 $\mu \mathrm{m}$ disappeared. Furthermore, the HA ceramics prepared via the traditional method (i.e., the green bodies consisted of the HA powders and HPMC were dried naturally and sintered at $1100{ }^{\circ} \mathrm{C}$ for $6 \mathrm{~h}$ ) also were tested, and Fig. 4(c) shows that the prepared ceramics were compact with large HA grains and had negligible porosity. The compared results demonstrated that the gel indeed acted as the roles of pore templates.

Taken together, above results demonstrated that in the gel-freeze casting technique, both water and gel in green bodies acted as pore templates. The pores with diameter $<1 \mu \mathrm{m}$ resulted from the gel and the pores with diameter $>1 \mu \mathrm{m}$ was attributable to water, which transferred into ice during freeze-drying, and thereby became pore templates.

The shrinkage of ceramics after sintering was investigated. Interestingly, Fig. 5(a) shows that the shrinkage ratio of the sintered ceramics was in direct proportion to the HA content in green bodies. Such result means that the porosity of the sintered ceramics presented a "Matthew effect", i.e., the green bodies with high porosity formed the ceramics with higher porosity and the ones with low porosity formed the ceramics with lower porosity after high temperature
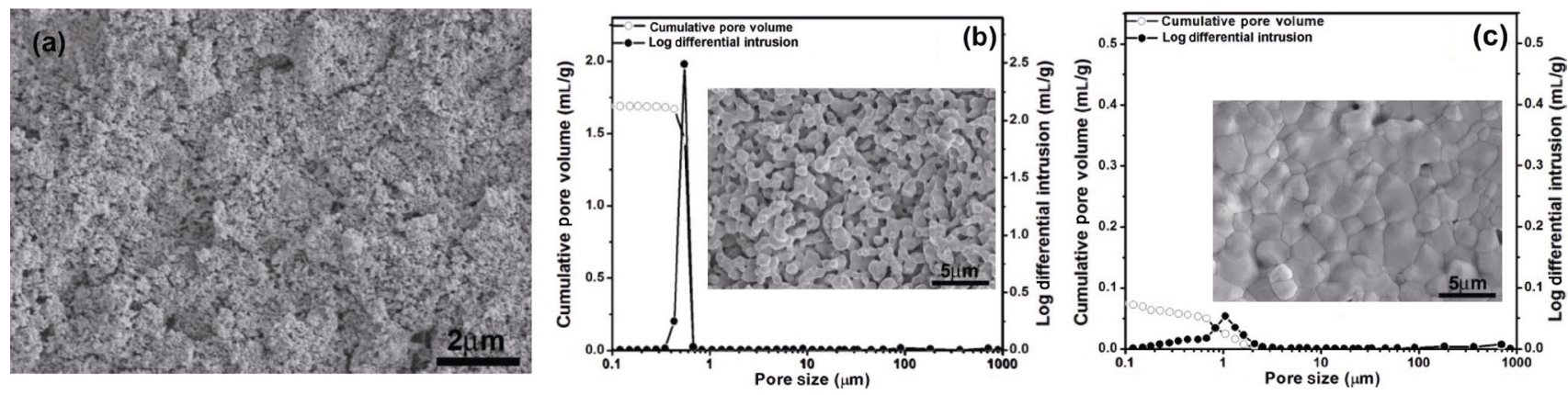

Fig. 4 (a) SEM image of the gel cast green bodies with $48 \mathrm{wt} \%$ HA. MIP and SEM image (inserted in MIP) of the HA ceramics prepared (b) from the gel cast green bodies with $48 \mathrm{wt} \% \mathrm{HA}$ or (c) from the green bodies only containing HA powders and HPMC (above ceramics were sintered at $1100{ }^{\circ} \mathrm{C}$ for $6 \mathrm{~h}$ ). 

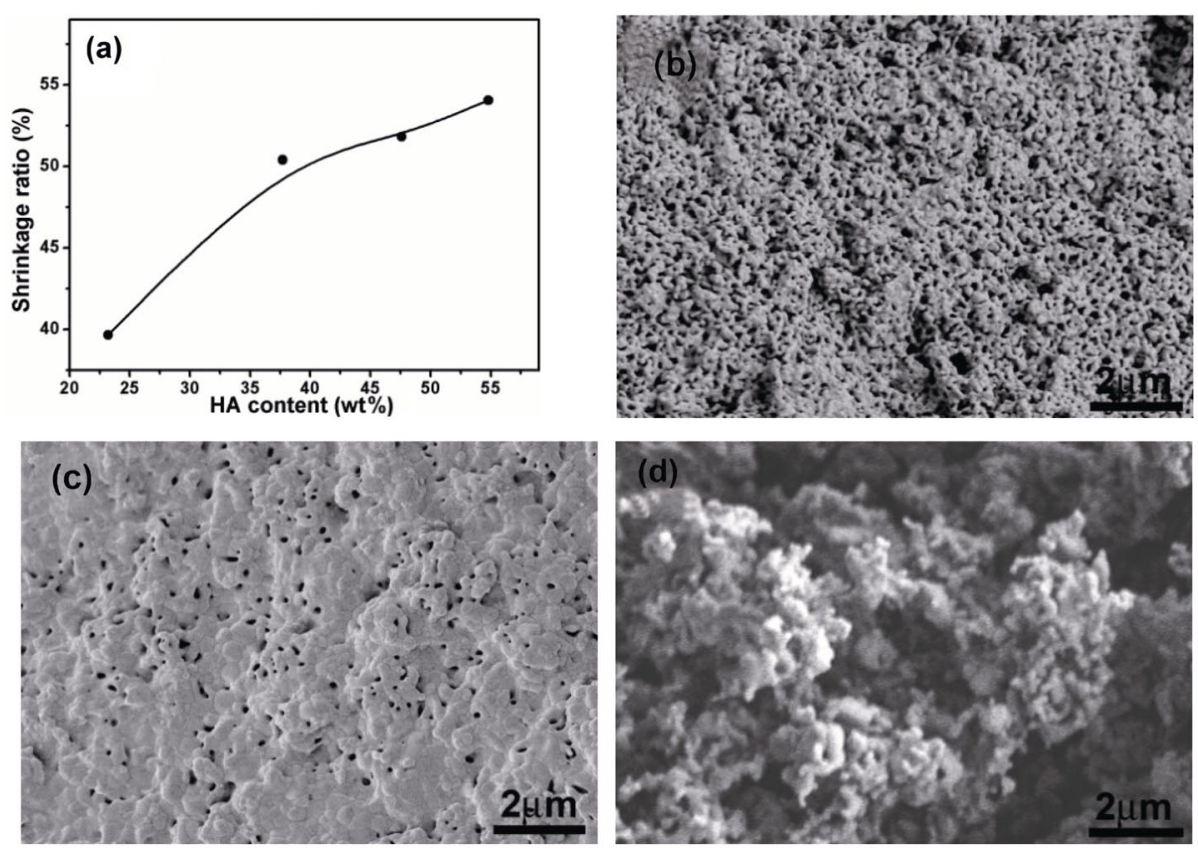

Fig. 5 (a) Shrinkage ratio of the gel-freeze cast HA ceramics (all samples were sintered at $1100{ }^{\circ} \mathrm{C}$ for $6 \mathrm{~h}$ ). SEM images of the HA ceramics prepared from the green bodies only containing HA and HPMC (the green bodies were sintered at (b) $850{ }^{\circ} \mathrm{C}$ and (c) $900{ }^{\circ} \mathrm{C}$ for $1 \mathrm{~h}$. (d) SEM image of the HA ceramics prepared from the $48 \mathrm{wt} \%$ HA-contained green bodies, which were sintered at $1000{ }^{\circ} \mathrm{C}$ for $2 \mathrm{~h}$.

sintering. To understand such phenomenon, a low temperature sintering was performed to the compact green bodies (only contain HA powders and HPMC) and porous gel-freeze green bodies ( $48 \mathrm{wt} \% \mathrm{HA}$ ). In the compact green bodies, Fig. 5(b) shows that after the green bodies were sintered at $850{ }^{\circ} \mathrm{C}$ for $1 \mathrm{~h}$, the mergence/fusion of the HA nanocrystals occurred. When the sintering temperature reached $900{ }^{\circ} \mathrm{C}$ (for $1 \mathrm{~h}$ ), the HA nanocrystals almost merged/fused completely and formed large HA grains (Fig. 5(c)). By comparison, in the porous gel-freeze green bodies, Fig. 5(d) shows that the green bodies even were sintered at $1000{ }^{\circ} \mathrm{C}$ for $2 \mathrm{~h}$, the merging/fusing degree of the HA nanocrystals was low. Above results showed that the nanocrystal-nanocrystal distance in green bodies played key roles in mediating the mergence/fusion of the HA nanocrystals and subsequently cascading the shrinkage, grain size, and interspace-constructed through-pores of the sintered ceramics. That is, the lower HA nanocrystal density in green bodies, the lower merging/fusing degree of the HA nanocrystals, thereby resulting in lower shrinkage ratio, smaller HA grains, and larger pore size and porosity.

Finally, mechanical strength of the sintered HA ceramics was tested. Figure 6 shows that the compressive strength was in direct proportion to the

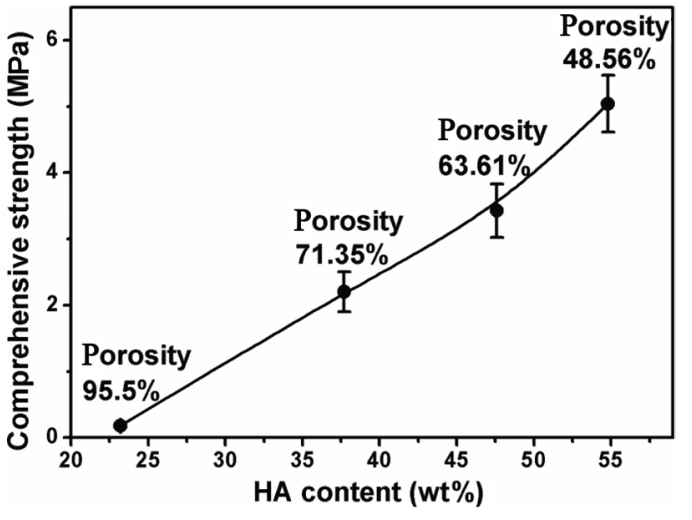

Fig. 6 Compressive strength of the gel-freeze cast HA ceramics which were sintered at $1100{ }^{\circ} \mathrm{C}$ for $6 \mathrm{~h}$ (mean \pm s.d., $n=5$ ).

HA content in green bodies. For practical applications, the through-porous ceramics with high compressive strength is no doubt desirable [26,27]. However, although the ceramics come from the green bodies with $55 \mathrm{wt} \%$ HA possessed higher strength (5.2 MPa), these ceramics had low porosity $(48.56 \%$, Table 3$)$. In contrast, the ceramics prepared from the $23 \mathrm{wt} \%$ HA-contained green bodies had very low compressive strength $(0.17 \mathrm{MPa})$. Therefore, the through-porous HA ceramics, prepared from the green bodies with $\sim 38-48 \mathrm{wt} \%$ and possessing proper compressive 
strength (2.2-2.7 MPa) and porosity (63.61\%-71.35\%, Table 3), are optimal for practical applications (e.g., chromatography [2], catalysis [3], gas sensing [4], etc.).

\section{Conclusions}

In this work we demonstrated that the use of the gel-freeze casting technique was available to prepare the through-porous HA monolithic ceramics and such combination of the gel casting and freeze casting complemented respective shortcomings. In the green body preparation, whatever the HA content in green bodies was, the use of the gel-freeze casting could impede the deformation of green bodies and retained desirable mechanical strength of green bodies. The existence of gel in green bodies inhibited the growth of ice crystals, thus impeding the formation of the lamellar microstructures in green bodies. Instead, irregular pore channels formed, which subsequently transferred into through-pores after the green bodies were sintered. In the HA ceramic sintering, experiments demonstrated that both water and gel acted as pore templates, and the pores with diameter $<1 \mu \mathrm{m}$ resulted from the gel and the pore with diameter $>1 \mu \mathrm{m}$ water, and pore size, porosity, and compressive strength of the prepared ceramics depended on and could be adjusted by the HA content. Furthermore, the shrinkage tests of the sintered ceramics demonstrated that the density of the HA nanocrystals in green bodies played vital roles in mediating the shrinkage, grain size, pore size, and porosity of the sintered ceramics. The gel-freeze casting technique reported here in the preparation of through-porous ceramics is simple, repeatable, and cost-effective, therefore is believed being hopeful for scale fabrication of different through-porous ceramics.

\section{Acknowledgements}

This work was supported by the National Natural Science Foundation of China (Grant No. 31570977).

\section{References}

[1] Chen Y, Sun ZH, Li YY, et al. Preparation and biological effects of apatite nanosheet-constructed porous ceramics. $J$ Mater Chem B 2017, 5: 807-816.

[2] Yamasaki Y, Yokoyama A, Ohnaka A, et al. High-performance hydroxyapatite chromatography of nucleic acids. J Chromatogr 1989, 467: 299-303.

[3] Low HR, Avdeev M, Ramesh K, et al. Zinc hydroxyapatite catalyst for decomposition of 2-propanol. Adv Mater 2012, 24: 4175-4179.

[4] Mene RU, Mahabole MP, Sharma R, et al. Enhancement in $\mathrm{CO}$ gas sensing properties of hydroxyapatite thick films: Effect of swift heavy ion irradiation. Vacuum 2011, 86: 66-71.

[5] Jiang SD, Yao QZ, Zhou GT, et al. Fabrication of hydroxyapatite hierarchical hollow microspheres and potential application in water treatment. J Phys Chem C 2012, 116: 4484-4492.

[6] Tanaka N, Kobayashi H, Nakanishi K, et al. A new type of chromatographic support could lead to higher separation efficiencies. Anal Chem 2001, 73: 420A-429A.

[7] Descamps M, Richart O, Hardouin P, et al. Synthesis of macroporous $\beta$-tricalcium phosphate with controlled porous architectural. Ceram Int 2008, 34: 1131-1137.

[8] Liu B, Lin PH, Shen Y, et al. Porous bioceramics reinforced by coating gelatin. J Mater Sci: Mater Med 2008, 19: 1203-1207.

[9] Hong YL, Fan HS, Li B, et al. Fabrication, biological effects, and medical applications of calcium phosphate nanoceramics. Mater Sci Eng R Rep 2010, 70: 225-242.

[10] Deville S, Saiz E, Nalla RK, et al. Freezing as a path to build complex composites. Science 2006, 311: 515-518.

[11] Descamps M, Duhoo T, Monchau F, et al. Manufacture of macroporous $\beta$-tricalcium phosphate bioceramics. $J$ Eur Ceram Soc 2008, 28: 149-157.

[12] Engin NO, Tas AC. Manufacture of macroporous calcium hydroxyapatite bioceramics. J Eur Ceram Soc 1999, 19: 2569-2572.

[13] Fu Q, Rahaman MN, Dogan F, et al. Freeze casting of porous hydroxyapatite scaffolds. I. Processing and general microstructure. J Biomed Mater Res 2008, 86B: 125-135.

[14] Reed JS. Critical issues and future directions in powder forming processes. In: Ceramic Transactions, Vol. 1, Ceramic Powder Science II (B). Messing GL, Fuller ER Jr., Hausner H, Eds. American Ceramic Society, 1987: 601-610.

[15] St Pierre PDS. Slip casting nonclay ceramics. In: Ceramic Fabrication Processes. Kingery WD, Ed. MIT Press, 1963: 45-51.

[16] Mangels JA. Injection molding ceramics. In: Proceedings of the 6th Annual Conference on Composites and Advanced Ceramic Materials: Ceramic Engineering and Science Proceedings, 2008.

[17] Young AC, Omatete OO, Janney MA, et al. Gelcasting of alumina. J Am Ceram Soc 1991, 74: 612-618.

[18] Omatete OO, Janney MA, Nunn SD. Gelcasting: From laboratory development toward industrial production. J Eur Ceram Soc 1997, 17: 407-413.

[19] Sepulveda P, Ortega FS, Innocentini MDM, et al. Properties of highly porous hydroxyapatite obtained by the gelcasting of foams. $J$ Am Ceram Soc 2000, 83: 3021-3024. 
[20] Ramay HR, Zhang MQ. Preparation of porous hydroxyapatite scaffolds by combination of the gel-casting and polymer sponge methods. Biomaterials 2003, 24: 3293-3302.

[21] Raynaud S, Champion E, Bernache-Assollant D, et al. Calcium phosphate apatites with variable $\mathrm{Ca} / \mathrm{P}$ atomic ratio I. Synthesis, characterisation and thermal stability of powders. Biomaterials 2002, 23: 1065-1072.

[22] Padilla S , García-Carrodeguas R , Vallet-Regí M . Hydroxyapatite suspensions as precursors of pieces obtained by gelcasting method. J Eur Ceram Soc 2004, 24 : 2223-2232.

[23] Ortega FS, Sepulveda P, Pandolfelli VC. Monomer systems for the gelcasting of foams. J Eur Ceram Soc 2002, 22: 1395-1401.

[24] Deville S, Saiz E, Tomsia AP. Freeze casting of hydroxyapatite scaffolds for bone tissue engineering. Biomaterials 2006, 27: 5480-5489.

[25] Scotti KL, Dunand DC. Freeze casting-A review of processing, microstructure and properties via the open data repository, FreezeCasting.net. Prog Mater Sci 2018, 94: 243-305.
[26] Munz D, Fett T. Ceramics: Mchanical Properties, Failure Behaviour, Materials, Selection. Springer, 1999.

[27] Mattoni MA, Yang JY, Levi CG, et al. Effects of matrix porosity on the mechanical properties of a porous-matrix, all-oxide ceramic composite. J Am Ceram Soc 2001, 84: 2594-2602.

Open Access This article is licensed under a Creative Commons Attribution 4.0 International License, which permits use, sharing, adaptation, distribution and reproduction in any medium or format, as long as you give appropriate credit to the original author(s) and the source, provide a link to the Creative Commons licence, and indicate if changes were made.

The images or other third party material in this article are included in the article's Creative Commons licence, unless indicated otherwise in a credit line to the material. If material is not included in the article's Creative Commons licence and your intended use is not permitted by statutory regulation or exceeds the permitted use, you will need to obtain permission directly from the copyright holder.

To view a copy of this licence, visit http://creativecommons. org/licenses/by/4.0/. 